\title{
Evre IV küçük hücreli dışı akciğer kanserli hastaların sağkalımını etkileyen faktörler
}

\author{
The factors effecting survival of stage IV non-small cell lung cancer patients
}

Turgut Kaçan*, Nalan Akgün Babacan, Birsen Yücel, Saadettin Kılıçkap, Ebru Atasever Akkaş, Mehmet Metin Şeker, Mehmet Fuat Eren, Ayfer Ay Eren

Tıbbi Onkoloji Bilim Dalı (Dr. T. Kaçan, Yrd. Doç. Dr. N. A. Babacan, Yrd. Doç. Dr. M. M. Şeker, Doç. Dr. S. Kılıçkap), Radyasyon Onkolojisi Anabilim Dalı (Yrd. Doç. Dr. B. Yücel Yrd. Doç. Dr. M. F. Eren, Yrd. Doç. Dr. A. A. Eren), Cumhuriyet Üniversitesi Tıp Fakültesi, TR-58140 Sivas, Radyasyon Onkolojisi Kliniği (Dr. E. A. Akkaş), Sivas Numune Hastanesi, TR-58040 Sivas

\begin{abstract}
Özet
Amaç. Bu çalışmada evre IV küçük hücreli dışı akciğer kanserli hastalarda tedavi öncesi prognostik faktörlerin sağkalım üzerine etkilerinin incelenmesi amaçlandı. Yöntem: Bu çalışma 2006-2011 tarihleri arasında merkezimize tedavi edilen evre IV küçük hücreli dışı akciğer kanserli 113 hastanın dosyalarının retrospektif incelenmesi ile yapıldı. Hastalara ait demografik, klinik ve histopatolojik veriler hasta dosya ve hastane kayıtları incelenerek elde edildi. Kontrole gelmemiş hastalar sağkalım analizi için, izin alınarak kimlik sorgulama sisteminde sorgulandı. Analiz için sıklık testleri, Mann-Whitney U testi ve Kaplan-Meier analizi kullanıldı. Bulgular. Yüzü (\%88) erkek, 13'ü (\%12) kadın toplam 113 hastanın verisi analiz edildi. Ortanca yaş 62 (37-82) idi. Sigara kullanımı 90 (\%80) hastada, aile hikayesi 27 (\%24) hastada, komorbidite 40 (\%35) hastada mevcuttu. Histopatolojik alt tip olarak 24 (\%21) hasta epidermoid, 30 (\%27) hasta adenokarsinom, 3 (\%2) hasta nöroendokrin alt tipine sahipti. Ellialtı (\%50) hastanın ise histopatolojik alt tipi belirlenememişti. En sık rastalanan Eastern Cooperative Oncology Group Perfromance Statusu ECOG 1 idi. En sık metastaz yerleri beyin (\%35), kemik (\%32), karaciğer (\%21) ve karş1 akciğer (\%18) idi. Hastaların 83'üne (\%73) kemoterapi uygulanırken 30'una (\%27) destek tedavisi verildi. Analjezik kullanımı $84(\% 74)$ hastada var iken palyatif radyoterapi 69 (\%61) hastaya uyguland1. Ortanca takip 8 ay (1-47), ortanca sağkalım 8 ay idi. Bir yıllık genel sağkalım \%35 olarak tespit edildi. Eastern Cooperative Oncology Group Perfromance Statusu $(p<0,001)$, kemoterapi uygulamas1 $(p<0,001)$, tedavide cisplatin $(p<0,001)$ ve docetaxel $(p=0,043)$ kullanımı, laktik dehidrogenaz yüksekliği $(\mathrm{p}=0,007)$ sağkalımı belirleyen prognostik faktörlerdi. Kemoterapi uygulaması $(p<0,001)$ ve laktik dehidrogenaz yüksekliği $(p=0,004)$ ise bağımsız prognostik faktörlerdi. Sonuç. Evre IV küçük hücreli dışı akciğer kanserinde sağkalımı etkileyen en önemli prognostik faktörler hastaya kemoterapi uygulanması ve laktik dehidrogenaz yüksekliği olarak tespit edildi.
\end{abstract}

Anahtar sözcükler: Evre IV küçük hücreli dış1 akciğer kanseri, sağkalım, prognosis

\begin{abstract}
Aim. The purpose of this study is to examine the prognostic factors effecting the survival of stage IV non-small cell lung cancer patients. Method. Demographic, clinical and histopathologic data from 2006 to 2011 were collected from non-small cell lung cancer patients who were treated in our clinic. With the permission of the patients who didn't attend to routine follow-ups, their names were searched in identification interrogation system in order to use their identity information in survival analysis. In order to analyze frequency distributions, Mann-Whitney U test and KaplanMeier survival analysis were used. Results. A hundred (88\%) male, 13 (12\%) female of total 113 patients data were analyzed. The mean age was $62(37-82) .90(80 \%)$ of the patients were smokers, family history existed in $27(24 \%)$ of the patients, $40(35 \%)$ of patients were with comorbidities. According to the histopathological aspect; 24 (21\%) patients were epidermoid, 30 (27\%) adenocarsinoma, 3 (2\%) neuroendocrine, $56(50 \%)$ patients had unspecified non-small cell lung carcinoma. The most common Eastern Cooperative Oncology Group Perfromance Status was ECOG 1. Frequent sites of metastasis: 40 (35\%) brain, 36 (32\%) bone, 24 (21\%) liver, 20 (18\%) opposite lung. Chemotherapy was given to $83(73 \%)$ patient whereas supportive therapy was given to $30(27 \%)$ of the patients. Pain-killers were used in $84(74 \%)$ patients, palliative radiotherapy
\end{abstract}


was apllied to $69(61 \%)$. Median follow-up was 8 months (1-47), median survival was 8 months. One-year overall survival was 35 Eastern Cooperative Oncology Group Perfromance Status $(\mathrm{p}<0.001)$, and chemotherapy $(\mathrm{p}<0.001)$, and usage of cisplatin $(\mathrm{p}<0.001)$ and docetaxel $(\mathrm{p}=0.043)$ during the treatment, increased levels of lactic dehydrogenase $(p=0.007)$ were the prognostic factors effecting the survival. Chemotherapy $(\mathrm{p}<0.001)$ and high lactic dehydrogenase levels $(\mathrm{p}=0.004)$ were the independent prognostic factors. Conclusion. In stage IV non-small cell lung cancer the most important prognostic factors effecting the survival are chemotherapy and elevated lactic dehydrogenase levels.

Keywords: Stage IV non-small cell lung cancer, survival, prognosis

Geliş tarihi/Received: 02 Şubat 2013; Kabul tarihi/Accepted: 11 Temmuz 2013

\section{*İletişim adresi:}

Dr. Turgut Kaçan, Onkoloji Anabilim Dalı, Cumhuriyet Üniversitesi Tıp Fakültesi, TR-58140

Sivas. E-posta: kacanturgut@gmail.com

\section{Giriş}

Akciğer kanseri dünyada en sık karşılaşılan kanserlerdendir [1]. Yaklaşık olarak \%95 kadarı küçük hücreli akciğer kanseri (KHAK \%15) ve küçük hücreli diş1 akciğer kanseri (KHDAK \%80) olarak sınıflandırılır. Bu ayrım hastalığın evrelendirilmesi, tedavi kararı ve prognoz açısından önemlidir. Diğer hücre tiplerinden kaynaklan akciğer kanserleri ise $\% 5$ kadardir [2].

Yaklaşık olarak KHDAK hastalarının üçte ikisi tanı anında ileri evredir [3]. Yeni tedavi modalitelerinin gelişmesi ile birlikte ileri evre KHDAK hastalarının yaşam süreleri de artmıştır. Ancak hastalığın kontrolü halen zordur [4]. Kişisel ve tümöre ait faktörlerin yanısıra uygulanan kemoterapi rejimleri de yaşam süresini etkilemektedir. Hastalı̆̆ın alt grubu, hastalığın evresi, Eastern Cooperative Oncology Group Perfromance Status (ECOG PS), kilo kayb1, cinsiyet, serum laktat dehidrogenaz (LDH) düzeyi prognostik faktörlerdir [5]. İleri evre KHDAK hastalarında tedavi kararı verilirken prognostik faktörlerin değerlendirilmesi son derece önemlidir

Bu çalışmada evre IV Küçük hücreli dışı akciğer kanseri sağkalımı etkileyen prognostik faktörlerin incelenmesi amaçlanmıştır.

\section{Gereç ve yöntem}

Bu çalışmada Cumhuriyet Üniversitesi Onkoloji Merkezi'nde takip ve tedavi edilen evre IV KHDAK hastalarda prognostik faktörler ve sağkalım arasındaki ilişki irdelenmeye çalışıldı. Bu nedenle hasta dosyaları ve hastane kayıtları retrospektif olarak incelendi. Hastalara ait yaş ve cinsiyet gibi demografik verilerin yanı sıra, tümörün histopatolojik alt grupları, metastaz varlığı gibi hastalık ilişkili faktörler kaydedildi. Hastaların performans durumu ECOG PS ile değerlendirildi [6].

Hastalara ait tanı anındaki tam kan sayımı, total biyokimya, LDH (Normal: 120-246 U/L) gibi parametreler kaydedildi. Çalışmaya histopatolojik olarak KHDAK tanısı almış evre IV hastalar dahil edildi. KHAK ve metastatik olmayan hastalar çalışma dışı bırakıldı.

\section{Ístatistiksel analiz}

Analiz için SPSS versiyon 15.0 ile sıklık testleri, Mann-Whitney U testi kullanılırken, sağkalım analizi için Kaplan-Meier yöntemi kullanıldı. Sağkalım üzerine bağımsız faktörleri değerlendirmek için ise çok değişkenli analiz (cox regresyon analizi) yapıldı. P değeri $<0,05$ olması istatiksel olarak anlamlı kabul edildi. Çalışma öncesinde verilerin toplanması, değerlendirilmesi, analizi ve yorumlanabilmesi için Cumhuriyet Üniversitesi Tip Fakultesi etik kuruldan onay alındı. 


\section{Bulgular}

Çalışmada 2006-2011 tarihleri arasında bölümümüze başvuran verileri yeterli olan, evre IV KHDAK tanısı almış toplam 113 hastanın verileri analiz edildi. Çalışmaya alınan hastaların ortanca yaşı 62 (37-82) idi. Erkek hastalarda ortanca yaş 62 (37-82) iken kadın hastalarda 67 (50-79) olup fark istatistiksel olarak anlamlı değildi $(\mathrm{p}=0.471)$. Hastaların demografik ve klinik özellikleri tablo 1'de gösterilmektedir.

En sik metastaz yerleri sırasıyla; beyin (\%35), kemik (\%32), karaciğer (\%21), karş1 akciğer (\%18) idi. Hastaların 83'üne (\%73) kemoterapi uygulanırken 30'una (\%27) destek tedavisi verildi. Hastaların 69'una (\%61) palyatif radyoterapi uyguland1. Analjezik ihtiyac1 ise 84 (\%74) hastada oldu.

Ortanca izlem süresi 8 ay (1-47) idi. 1-yıllık genel sağkalım \%35, 2-yıllık sağkalım \%9 idi. Hastaların prognostik özellikleri incelendiğinde; cinsiyet, yaş, histopatoloji, kilo kaybı, anemi, kemoterapi protokolleri sağkalmı etkilemezken, ECOG performans durumu, LDH yüksekliği, kemoterapi uygulaması, platin ve taksan uygulamaları sağkalımı anlamlı etkileyen prognostik faktörlerdi. Tablo 2'de tek değişkenli analizde sağkalımı etkileyen prognostik faktörler gösterilmiştir.

Tablo 1. Hastaların demografik ve klinik özellikleri.

\begin{tabular}{|c|c|}
\hline Hastaya ait özellikler & Hasta sayısı (n, \%) \\
\hline \multicolumn{2}{|l|}{ Cinsiyet } \\
\hline Erkek & $100(89)$ \\
\hline Kadın & $13(11)$ \\
\hline \multicolumn{2}{|l|}{ Yaş } \\
\hline$\leq 65$ yaş & $67(59)$ \\
\hline$>65$ yaş & $46(41)$ \\
\hline Sigara & $90(80)$ \\
\hline Alkol & $9(8)$ \\
\hline Aile hikayesi & $27(24)$ \\
\hline Kilo kaybı & $60(47)$ \\
\hline Komorbidite & $24(21)$ \\
\hline \multicolumn{2}{|l|}{ Performans durumu } \\
\hline ECOG-0 & $20(18)$ \\
\hline ECOG-1 & $43(38)$ \\
\hline ECOG-2 & $35(31)$ \\
\hline ECOG-3 & $15(15)$ \\
\hline \multicolumn{2}{|l|}{ Anemi } \\
\hline Yok & $37(49)$ \\
\hline Var & $38(51)$ \\
\hline \multicolumn{2}{|l|}{ LDH } \\
\hline$\leq 246$ & $37(64)$ \\
\hline$>246$ & $21(36)$ \\
\hline \multicolumn{2}{|l|}{ Histopatoloji } \\
\hline Epidermoid & $24(21)$ \\
\hline Adeno & $30(27)$ \\
\hline Non-small & $59(52)$ \\
\hline \multicolumn{2}{|l|}{ Tedavi } \\
\hline Kemoterapi & $83(73)$ \\
\hline Palyatif tedavi & $30(27)$ \\
\hline \multicolumn{2}{|c|}{ Kemoterapi protokolleri } \\
\hline Platin+docetaxel & $23(29)$ \\
\hline Platin+paclitaxel & $29(37)$ \\
\hline Platin+gemsitabin & $17(22)$ \\
\hline Platin+etoposid & $8(10)$ \\
\hline Diğer & $6(8)$ \\
\hline
\end{tabular}

LDH ve kemoterapi uygulaması ayrıca sağkalımı etkileyen bağımsız prognostik faktörlerdi (Tablo 3). Şekil 1 ve 2'de LDH düzeyine ve kemoterapi uygulamalarına ait sağkalım eğrileri görülmektedir. 
Tablo 2. Evre IV küçük hücreli dışı akciğer kanseri hastalarında sağkalımı etkileyen prognostik faktörler.

\begin{tabular}{|c|c|c|c|c|c|}
\hline \multicolumn{6}{|c|}{ Tek değişkenli analiz } \\
\hline & $\begin{array}{l}\text { Hasta } \\
\text { sayısı }\end{array}$ & $\begin{array}{l}\text { Ortanca sağkalım } \\
\text { (ay) }\end{array}$ & $\begin{array}{l}1 \text { yıllık genel } \\
\text { sağkalım (\%) }\end{array}$ & $\begin{array}{l}2 \text { yıllık genel } \\
\text { sağkalım (\%) }\end{array}$ & $\begin{array}{l}\mathbf{p} \\
\text { değeri }\end{array}$ \\
\hline \multicolumn{6}{|c|}{ 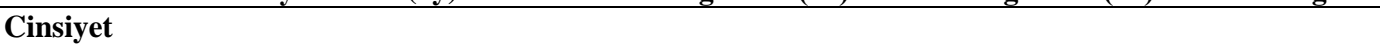 } \\
\hline Erkek & 100 & 8 & 36 & 10 & \multirow{2}{*}{0,840} \\
\hline Kadın & 13 & 7 & 21 & - & \\
\hline \multicolumn{6}{|l|}{ Yaş } \\
\hline 65 yaş altı & 67 & 9 & 39 & 10 & \multirow{2}{*}{0,060} \\
\hline 65 yaş üzeri & 46 & 6 & 24 & - & \\
\hline \multicolumn{6}{|c|}{ Performance status } \\
\hline ECOG-0 & 20 & 9 & 48 & 19 & \multirow{4}{*}{$<0,001$} \\
\hline ECOG-1 & 43 & 11 & 48 & 11 & \\
\hline ECOG-2 & 35 & 6 & 25 & - & \\
\hline ECOG-3 & 15 & 2 & - & - & \\
\hline \multicolumn{6}{|l|}{ LDH } \\
\hline$<246 \mathrm{U} / \mathrm{L}$ & 37 & 12 & 54 & 20 & \multirow{2}{*}{0,007} \\
\hline$\geq 246 \mathrm{U} / \mathrm{L}$ & 21 & 9 & 22 & - & \\
\hline \multicolumn{6}{|l|}{ Anemi } \\
\hline Yok & 37 & 12 & 52 & 14 & \multirow{2}{*}{0,063} \\
\hline Var & 38 & 8 & 36 & 3 & \\
\hline \multicolumn{6}{|l|}{ Histopatoloji } \\
\hline Epidermoid & 24 & 7 & 25 & 10 & \multirow{2}{*}{0,247} \\
\hline Adeno & 30 & 11 & 50 & 12 & \\
\hline \multicolumn{6}{|l|}{ Kilo kaybı } \\
\hline Yok & 53 & 8 & 33 & 10 & \multirow[t]{2}{*}{0,543} \\
\hline Var & 60 & 8 & 34 & 8 & \\
\hline \multicolumn{6}{|l|}{ Tedavi } \\
\hline KT & 83 & 11 & 48 & 12 & \multirow{2}{*}{$<0,001$} \\
\hline Palyatif tedavi & 30 & 2 & - & - & \\
\hline \multicolumn{6}{|l|}{ Platin } \\
\hline Yok & 33 & 2 & - & - & \multirow{2}{*}{$<0,001$} \\
\hline Var & 80 & 11 & 48 & 10 & \\
\hline \multicolumn{6}{|l|}{ Taxan } \\
\hline Yok & 52 & 4 & 25 & 7 & \multirow[t]{2}{*}{0,003} \\
\hline Var & 61 & 10 & 41 & 10 & \\
\hline \multicolumn{6}{|l|}{ KT protokol } \\
\hline Platin+docetaxel & 23 & 11 & 43 & 6 & \multirow{3}{*}{0,837} \\
\hline Platin+paclitaxel & 29 & 8 & 30 & 8 & \\
\hline Platin+gemsitabin & 17 & 13 & 5 & - & \\
\hline
\end{tabular}

Tablo 3. Sağkalım üzerine bağımsız risk faktörleri (cox regresyon analizi).

\begin{tabular}{llll}
\hline & P değeri & Exp $(\mathbf{B})$ & \%95 güven aralığı \\
\hline LDH & 0,004 & 2,6 & $1,3-4,9$ \\
Tedavi & $<0,001$ & 6,1 & $2,3-15,8$ \\
\hline
\end{tabular}

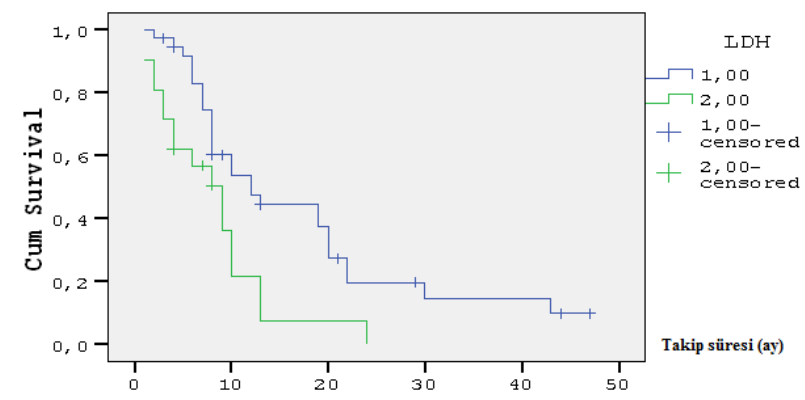

Şekil 1. LDH düzeyine göre sağkalım. 


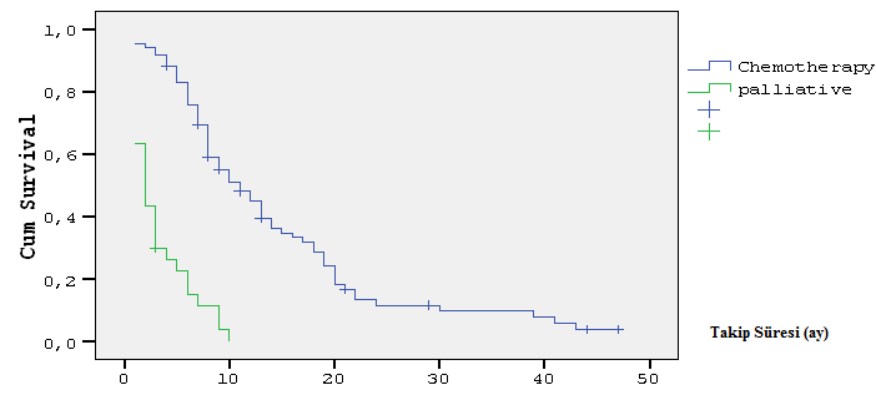

Şekil 2. Tedaviye göre sağkalım.

\section{Tartışma}

Akciğer kanseri tüm dünyada kansere bağlı en önemli ölüm nedenlerinden biridir [1]. Tüm akciğer kanserlerinin yaklaşık \%80'i KHDAK'dir [2]. Nitrosaminlerde azalma olmaksızın, nikotini azaltılmış filtreli sigara kullanımı, sigara içerisindeki değişiklikler skuamöz hücreli ve küçük hücreli akciğer kanserlerinde azalmaya, adenokanserlerde ise artışa neden olmaktadır. $\mathrm{Bu}$ nedenlerle son yıllarda adenokarsinom oranı giderek artmaktadır ve sıklığı yaklaşık olarak \%38'dir. [1, 7]. Bu çalışmada da adenokarsinom $\% 27$ ile en s1k rastlanan alt tip idi.

İleri evre küçük hücreli dışı akciğer kanserinde prognoz kemoterapi, radyoterapi ve kombine tedavilerinin iyi yanıtlarına rağmen kötü olup olguların bir yıllık yaşam süresi \%30-35'tir. İki yıldan uzun yaşam süresi ise \%11'dir [8-10]. Çalışmamızda bir yıllık sağkalım oranı $\% 35$ iken iki yıllık sağkalım oranı $\% 9$ olarak saptandı. Bu oran literatürdekine benzerdi.

KHDAK histopatolojik alt tipin yaşam süresini etkilediği bilinmektedir. İleri evre KHDAK alt tipi incelendiğinde bronkoalveler karsinom tipinin diğer alt tiplere göre daha iyi sağkalıma sahiptir [11]. Bu çalışmada histopatolojik alt tipler incelendiğinde yaşam süresini anlamlı olarak etkilemediği saptandı.

Yapılan çalışmalarda ileri yaş grubunda olan hastaların komorbid hastalıklarının olması, komorbid hastalıklar nedeniyle performanslarının daha da kötü olması, tedavi komplikasyonlarının daha fazla olması nedeniyle prognozları genç olan hastalara göre daha kötüdür. Yapılan bir çalışmada 65 yaş altı olguların 65 yaş üzeri olan olgulara göre daha iyi sağkalıma sahip olduğu bildirilmiştir [12]. Bu çalışmada ise 65 yaş altı ve üzeri hastaların sağkalımı arasında fark yoktu.

İleri evre KHDAK olgularda cinsiyetin sağkalım üzerine etkisinin değerlendirildiği çalışmalarda kadın cinsiyetin uzun sağkalım açısından bağımsız prognostik faktör olduğu bildirilmiştir $[13,14]$. Bu çalışmada erkek kadın oranı 7,7 bulunmuştur. Ülkemizde halen erkek cinsiyette yüksek oranda KHDAK saptanmaktadır. Literatürde kadın cinsiyetin daha uzun sağkalıma sahip olduğu bildirilse de bu çalışmada anlamlı bir fark saptanmadı. Ancak çalışmamızda kadın hasta sayısı oldukça azdı.

Beslenme sorunu olan ve kilo kaybı olan hastalar malnutrisyona kadar ilerleyebilmektedir. Mevcut tablonun ilerlemesi hem performans statusunun kötüleşmesine hem de anemi oluşumunun hızlanmasını kolaylaştırmaktadır. Beslenme bozukluğu, kötü performans statusu ve anemi birlikteliğinin ileri evre KHDAK hastalarında sağkalımı olumsuz etkilediği bilinmektedir. Beslenme programına alınan akciğer kanserli hastaların ise tedavi komplikasyonlarına daha az maruz kaldığ 1 bildirilmiştir. [15-19]. Bu çalışmada PS 0-1 olan olguların sağkalımının daha uzun olduğu saptandı. Kilo kaybı ve aneminin ise sağkalım üzerine etkisi gösterilememiş olsada hem kilo kaybının hemde aneminin düzeltilmesi hastanın yaşam kalitesinin yanı sıra performansını da düzeltebileceğinden önemlidir. 
KHDAK olan hastalarda LDH seviyesi yüksek seyredebilmektedir. İlaç toksisitesi gelişen ve nötropenik olan hastalarda LDH değerlerinin yüksek seyrettği bulunmuştur. Bu yükssekliğin de kötü prognoz ile ilişkili olduğu saptanmıştır [20, 21]. Bu çalışmada da yüksek LDH seviyesi olan olgularda da sağkalımın daha kısa olduğu ve bağımsız risk faktörü olduğu saptandı (Şekil 1).

Yeni gelişen kemoterapi ajanlarının üretilmesi ve tedavide kombinasyon seçeneklerinin artmas1 ile birlikte kemoterapi cevabı giderek artmaktadır. Kemoterapi alan hastaların destek tedavisine oranla sağkalımı daha uzundur. Özellikle genç KHDAK hastalarında klinik evrenin ve tedavi modaliteslerinin bağımsız prognostik faktör olduğu saptanmıştır [22]. Günümüzde ileri evre KHDAK'inde performansı iyi olan hastalarda standart tedavi yaklaşımı platin bazlı tedavilerdir. Platin bazlı tedaviler kanser ilişkili sağkalımı olumlu yönde etkilemektedir. Hem kanser ilişkili semptomların düzelmesinde hem de yaşam kalitesinde düzelme sağlamaktadır [23-25]. Bu çalışmada da kemoterapi alan hastaların sağkalımı kemoterapi almayanlara göre anlamlı derecede uzun olarak saptandı (Şekil 2). Ayrıca, kemoterapi uygulaması literatürdekine benzer şekilde bağımsız prognostik faktör olarak da tespit edildi. Kombinasyon kemoterapisinde sağkalım üzerine anlamlı fark yok iken kemoterapi ajanları ayrı ayrı değerlendirildiğinde taksanların (dosetaksel, paklitaxel) $(p=0,003)$ ve platinlerin (sisplatin, karboplatin) kullanımı sağkalımı olumlu etkilemiştir $(\mathrm{p}<0,001)$. Dosetaksel $(\mathrm{p}=0,043)$ ve sisplatin $(\mathrm{p}<0,001)$ tedavisi alan hastaların sağkalımı daha uzundu. Paklitaksel ve karboplatin alanlarda ise fark yoktu. Taksan ile kombine edilmiş kemoterapilerde ise sağkalım açısından anlamlı fark yoktu.

Sonuç olarak evre IV küçük hücre dışı akciğer kanserinde sağkalımı etkileyen en önemli prognostik faktörler hastaya kemoterapi uygulanması ve LDH yüksekliği olarak tespit edildi.

\section{Kaynaklar}

1. Jemal A, Bray F, Center MM, Ferlay J, Ward E, Forman D. 4. Global cancer statistics. CA Cancer J Clin 2011; 61: 69-90.

2. Silvestri GA, Tanoue LT, Margolis ML, Barker J, Detterbeck F; American College of Chest Physicians. The noninvasive staging of non-small cell lung cancer: the guidelines. Chest 2003; 123: 147S-156S.

3. Jemal A, Siegel R, Ward E, Hao Y, Xu J, Thun MJ. Cancer statistics, 2009. CA Cancer J Clin 2009; 59: 225-49.

4. Fossella F, Pereira JR, von Pawel J, Pluzanska A, Gorbounova V, Kaukel E, Mattson KV, Ramlau R, Szczesna A, Fidias P, Millward M, Belani CP. Randomized, multinational, phase III study of docetaxel plus platinum combinations versus vinorelbine plus cisplatin for advanced non-small-cell lung cancer: the TAX 326 study group. J Clin Oncol 2003; 21: 3016-24.

5. Wigren T. Confirmation of a prognostic index for patients with inoperable nonsmall cell lung cancer. Radiother Oncol 1997; 44: 9-15.

6. Oken MM, Creech RH, Tormey DC, Horton J, Davis TE, McFadden ET, Carbone PP. Toxicity and response criteria of the Eastern Cooperative Oncology Group. Am J Clin Oncol 1982; 5: 649-55.

7. Akkoçlu A, Savaş İ, Göksel T, Yılmaz U, Akciğer Kanseri Tanı ve Tedavi Rehberi. , Göksel T, Özlü T (eds), In: Akciğer ve Plevra Maliğniteleri Tedavisi Türk Toraks Derneği Okulu Kitabı, Sentez Matbaac1lık, Ankara, 2008; 9-11.

8. Socinski MA, Morris DE, Masters GA, Lilenbaum R; American College of Chest Physicians. Chemotherapeutic management of stage IV non-small cell lung cancer. Chest 2003; 123: 226-243.

9. Okamoto T, Maruyama R, Shoji F, Asoh H, Ikeda J, Miyamoto T, Nakamura T, Miyake T, Ichinose Y. Long-term survivors in stage IV non-small cell lung cancer. Lung Cancer 2005; 47: 85-91

10. Sugiura S, Ando Y, Minami H, Ando M, Sakai S, Shimokata K. Prognostic value of pleural effusion in patients with non-small cell lung cancer. Clin Cancer Res 1997; 3: 47-50. 
11. Hayes DN, Monti S, Parmigiani G, Gilks CB, Naoki K, Bhattacharjee A, Socinski MA, Perou C, Meyerson M. Gene expression profiling reveals reproducible human lung adenocarcinoma subtypes in multiple independent patient cohorts. J Clin Oncol 2006; 24: 5079-90.

12. Gore E, Movsas B, Santana-Davila R, Langer C. Evaluation and management of elderly patients with lung cancer. Semin Radiat Oncol 2012; 22: 304-10.

13. Charloux A, Hedelin G, Dietemann A, Ifoundza T, Roeslin N, Pauli G, Quoix E. Prognostic value of histology in patients with non-small cell lung cancer. Lung Cancer 1997; 17: 123-34.

14. Wigren T, Oksanen H, Kellokumpu-Lehtinen P. A practical prognostic index for inoperable non-small-cell lung cancer. J Cancer Res Clin Oncol 1997; 123: 25966.

15. Shinkai T, Eguchi K, Sasaki Y, Tamura T, Ohe Y, Kojima A, Oshita F, Miya T, Okamoto $\mathrm{H}$, Iemura $\mathrm{K}$, et al. A prognostic-factor risk index in advanced nonsmall-cell lung cancer treated with cisplatin-containing combination chemotherapy. Cancer Chemother Pharmacol 1992; 30: 1-6.

16. Paesmans M, Sculier JP, Libert P, Bureau G, Dabouis G, Thiriaux J, Michel J, Van Cutsem O, Sergysels R, Mommen P, et al. Prognostic factors for survival in advanced non-small-cell lung cancer: univariate and multivariate analyses including recursive partitioning and amalgamation algorithms in 1,052 patients. The European Lung Cancer Working Party. J Clin Oncol 1995; 13: 1221-30.

17. Scott HR, McMillan DC, Crilly A, McArdle CS, Milroy R. The relationship between weight loss and interleukin 6 in non-small-cell lung cancer. $\mathrm{Br} \mathrm{J}$ Cancer 1996; 73: 1560-2.

18. Sánchez-Lara K, Turcott JG, Juárez E, Guevara P, Núñez-Valencia C, OñateOcaña LF, Flores D, Arrieta O. Association of nutrition parameters including bioelectrical impedance and systemic inflammatory response with quality of life and prognosis in patients with advanced non-small-cell lung cancer: a prospective study. Nutr Cancer 2012; 64: 526-34.

19. Shintani Y, Ikeda N, Matsumoto T, Kadota Y, Okumura M, Ohno Y, Ohta M. Nutritional status of patients undergoing chemoradiotherapy for lung cancer. Asian Cardiovasc Thorac Ann 2012; 20: 172-6.

20. Cağlayan B, Fidan A, Salepçi B, Kiral N, Torun E, Salepçi T, Mayadağli A. Effects of prognostic factors and treatment on survival in advanced non-small cell lung cancer. Tuberk Toraks 2004; 52: 323-32.

21. Brueckl WM, Herbst L, Lechler A, Fuchs F, Schoeberl A, Zirlik S, Klein P, Brunner TB, Papadopoulos T, Hohenberger W, Hahn EG, Wiest GH. Predictive and prognostic factors in small cell lung carcinoma (SCLC)--analysis from routine clinical practice. Anticancer Res 2006; 26: 4825-32.

22. Xu CH, Yu LK, Zhang Y, Xie HY, Hao KK, Hu W, Xia N, Zhan P. Analysis of prognostic factors of non-small cell lung cancer in patients under 40 years of age. Zhonghua Zhong Liu Za Zhi 2012; 34: 703-5.

23. Azzoli CG, Baker S Jr, Temin S, Pao W, Aliff T, Brahmer J, Johnson DH, Laskin JL, Masters G, Milton D, Nordquist L, Pfister DG, Piantadosi S, Schiller JH, Smith R, Smith TJ, Strawn JR, Trent D, Giaccone G; American Society of Clinical Oncology. American Society of Clinical Oncology Clinical Practice Guideline update on chemotherapy for stage IV non-small-cell lung cancer. J Clin Oncol 2009; 27: 6251-66.

24. D'Addario G, Felip E; ESMO Guidelines Working Group. Non-small-cell lung cancer: ESMO clinical recommendations for diagnosis, treatment and follow-up. Ann Oncol 2009; 20: 68-70.

25. Custodio A, de Castro J. Strategies for maintenance therapy in advanced nonsmall cell lung cancer: current status, unanswered questions and future directions. Crit Rev Oncol Hematol 2012; 82: 338-60. 